\title{
A PUPILA NA FASE CRÔNICA DA DOENÇA DE CHAGAS E REAÇÃO À PILOCARPINA E À FENILEFRINA
}

\author{
João Antonio Prata, João Antonio Prata Junior, Cleudson Nery de Castro, \\ Vanize Macedo e Aluizio Prata
}

\begin{abstract}
Com objetivo de desenvolver metodologia para avaliar alteraçôes pupilares na fase crônica da doença de Chagas em ârea endêmica, foram examinados dez pacientes chagásicos e dez controles, pareados quanto ao sexo, idade e cor. O diâmetro e área pupilar, determinados com recursos de projeção e topografia, foram comparados nos dois grupos. Ambas as pupilas foram fotografadas, simultaneamente, com iluminaçâo padronizada. De cada individuo foram feitas três fotos sucessinas: inicial após 30 minutos da instilaçāo de colinio de pilocarpina a 0,1\% e após 30 minutos da innsitlação de colírio de fenilefrina a $3 \%$. As pupilas dos chagásicos diferiram das dos controles, de forma estatisticamente significante: maiores diâmetros e äreas iniciais; irregularidades nos contomos; maiores reduçôes percentuais em diâmetro e área após pilocarpina; maiores aumentos percentuais em diâmetro e ärea após fenilefrina. A metodogia foi considerada satisfatória e os resultados sugerem alterações no sistema nervoso autônomo ocular nos chagấsicos.
\end{abstract}

Palauras-chaves: Anisocoria. Pupila. Doença de Chagas.

O envolvimento ocular na doença de Chagas é descrito na fase aguda. As alterações na fase aguda adquirida, o conhecido sinal de Romaña, constituem-se basicamente de edema unilateral e indolor na região peri-orbitária, associado à hiperemia conjuntival, podendo ocorrer dacrioadenite. Na forma aguda zongênita são descritas alteraçôes do segmento posterior do olho, como edema de papila, hemorragias retinianas, coriorretinite, acometimento macular e opacidades vítreas ${ }^{1}$.

Em trabalho anterior quando evidenciamos a anisocoria em chagásicos crônicos em Mambaí, GO, sentimos a necessidade de estabelecer uma maneira mais eficaz para o estudo da pupila em paciente chagásico, na área endêmica?.

O objetivo deste trabalho foi: a) desenvolver metodologia com instrumental singelo, para exame da pupila em região endêmica, b) obter mais informações sobre as pupilas nos pacientes chagásicos, inclusive a resposta à pilocarpina e à fenilefrina.

Faculdade de Medicina do Triângulo Mineiro, Uberaba, MG; Escola Paulista de Medicina, Universidade Federal de São Paulo São Paulo, SP e Núcleo de Medicina Tropical e Vutrição da Universidade de Brasília, Brasília, DF.

Endereço para correspondência: Dr. João Antonio Prata, FMTM, Caixa Postal 118, 38001-970 Uberaba, MG.

Recebido para publicação em 02/10/95.

\section{MATERIAL E MÉTODOS}

No municípo de Mambaí, GO, região endêmica de doença de Chagas foram constituídos dois grupos de dez indivíduos cada. Um grupo, de pacientes com sorologia positiva para doença de Chagas (chagásicos) e o outro com sorologia negativa (controle) foram pareados quanto à idade, sexo e cor. $O$ examinador desconhecia se o paciente era ou não chagásico. Em exame oftalmológico anterior estes pacientes não apresentaram anisocoria nem alterações oftalmológicas eventualmente capazes de influenciar no diâmetro pupilar.

Realizamos o exame em três fases. Na fase 1 (inicial), a pupila foi fotografada. Na fase 2 , procedeu-se outra fotografia após 30 minutos da instilação de uma gota de colírio de pilocarpina a $0,1 \% \mathrm{em}$ ambos os olhos. $\mathrm{Na}$ fase 3 , nova fotografia após 30 minutos da administração de uma gota de colírio de fenilefrina a 3\%, portanto 60 minutos após a instilação da pilocarpina.

A documentação fotográfica da pupila foi feita por fotógrafo profissional, com câmara Cannon equipada com lente macro e flash eletrônico, a uma distância de $26 \mathrm{~cm}$. O paciente permaneceu durante todo o exame em uma sala de $3 \times 2 \mathrm{~m}$ sem janelas, com iluminação proveniente de uma lâmpada de $60 \mathrm{~W}$. As fotos foram realizadas no escuro, cerca de dois 
Prata JA, Prata Jinnior JA, Castro CN, Macêdo VO, Prata A. A pupila na fase crônica da doença de Chagas $e$ reação à pilocarpina e à fenillefrina. Revista da Sociedade Brasileira de Medicina Tropical 29:567-570, novdez, 1996.

segundos após apagada a luz. Uma vez feita cada fotografia a luz era novamente acesa até o momento da fotografia da fase seguinte. Ambas pupilas foram fotografadas simultaneamente.

As fotos foram projetadas em tela a uma distância padronizada que permitiu uma ampliação de 25 vezes, estando o projetor em posição ortogonal à tela. Desta forma, os contornos pupilares foram então reproduzidos em papel e os diâmetros vertical e horizontal determinados com paquímetro. Foram determinados para cada pupila, a forma, os diâmetros horizontal e vertical e a sua área. $\mathrm{O}$ cálculo da área da pupila foi procedido por técnicas de topografia, por profissional habilitado. A correção da magnificação foi executada com base na escala de conversão, obtida pela projeção de uma régua milimetrada fotografada nas mesmas condiçôes.

O diâmetro pupilar foi considerado como sendo o obtido da média aritmética entre o diâmetro horizontal e vertical. Consideramos haver anisocoria quando a diferença entre os diâmetros pupilares corrigidos foi superior a $0,3 \mathrm{~mm}$ na fase $1^{5}$. Na fase 2 (pilocarpina), calculamos a variação percentual do diâmetro e da área pupilar em relaçào ao valor encontrado na fase 1. Na fase 3 (fenilefrina), as variações percentuais foram calculadas em relação aos valores da fase 2 . Os reflexos pupilares foram pesquisados antes da instilação da pilocarpina.

Os exames oftalmológicos em Mambai foram realizados no mês de janeiro de 1995 e os cálculos feitos após o regresso.

O diagnóstico da doença de Chagas foi estabelecido pela sorologia positiva. Os pacientes chagásicos, pelo exame clínico, eletrocardiográfico e radiológico do tubo digestivo, foram subdivididos nas seguintes formas clinicas: indeterminada, cardíaca, digestiva e mista ${ }^{0}$.

Para cada grupo, chagásico e não chagásico, calculamos a média do diâmetro e da área das 20 pupilas, em cada uma das três fases. Para a análise estatística dos valores entre os dois grupos utilizamos o teste de Mann-Whitney. A freqüência de anisocoria foi comparada entre os grupos pelo teste exato de Fisher.

\section{RESULTADOS}

Os pares eram do mesmo sexo e cor. Quanto à idade, em três pares era igual, em dois havia diferença de um ano, em quatro de dois e em um de três anos. A idade média nos chagásicos foi $49,6 \pm 11,2(\mathrm{p}=0,9)$ e nos não chagásicos $50,510,8(\mathrm{p}=0,9)$. A anisocoria foi observada em $4(40 \%)$ pacientes do grupo chagásico e em 1 (10\%) do grupo controle (Tabela 1). O teste exato de Fisher não detectou diferenças estatisticamente significantes $(\mathrm{p}=0,3)$.

Tabela 1 - Anisocoria em pacientes cbagásicos em relação às formas clinicas.

\begin{tabular}{|c|c|c|c|}
\hline \multirow{2}{*}{$\begin{array}{l}\text { Pacientes } \\
\text { (pares) }\end{array}$} & \multicolumn{2}{|c|}{ Anisocoria } & \multirow{2}{*}{$\begin{array}{l}\text { Formas clinicas } \\
\text { dos chagásicos }\end{array}$} \\
\hline & Controles & Chagásicos & \\
\hline 1 & Não & $\operatorname{Sin}$ & Cardíaca \\
\hline 2 & Não & Não & Digestiva \\
\hline 3 & $\operatorname{Sim}$ & $\operatorname{Sim}$ & Indeterminada \\
\hline 4 & Näo & Nào & Disgestiva \\
\hline 5 & Nào & Nào & Indeterminada \\
\hline 6 & Não & Não & Indeterminada \\
\hline 7 & Não & $\sin$ & Indeterminada \\
\hline 8 & $\mathrm{Nāo}$ & Nāo & Digestiva \\
\hline 9 & Nāo & Nào & Cardiaca \\
\hline 10 & Nāo & $\mathrm{Sim}$ & Digestiva \\
\hline
\end{tabular}

Quanto ao tamanho das pupilas em milímetros, a comparaçāo dos pares mostrou que sete pacientes chagásicos tinham ambas as pupilas maiores do que a dos seus pares. Em dois elas eram menores e em um par uma pupila do chagásico era menor e a outra maior que o seu par. A média dos diâmetros das 20 pupilas dos chagásicos foi de $4,35 \mathrm{~mm}$ e a dos seus pares controles foi de $3,77 \mathrm{~mm}$, sendo esta diferença estatisticamente significante $(\mathrm{p}=0,007)$ (Tabela 2). Após a instilação de colírio de pilocarpina (fase 2) observou-se entre os chagásicos redução no diâmetro pupilar médio de $22,2 \%$ e nos controles $12,4 \%$, sendo as diferenças estatisticamente signifcantes $(\mathrm{p}=0,003)$. Após a instilação de fenilefrina (fase 3) houve aumento pupilar de 50,2\% em média nos chagásicos em comparação com $23,5 \%$ nos não chagásicos. Estes resultados foram estatisticamente significantes $(\mathrm{p}=0,004)$.

Tabela 2 - Diânetro pupilar médio e ărea pupilar média. iniciais e após pilocarpina e após fenilefrina.

\begin{tabular}{|c|c|c|c|}
\hline Pupila & Chagásico & Controle & $\mathrm{P}^{*}$ \\
\hline \multicolumn{4}{|c|}{ Diâmetro pupilar nédio (mm) } \\
\hline Inicial & $4.35 \pm 0.6$ & $3,77 \pm 0.5$ & 0.007 \\
\hline Após pilocarpina $0,1 \%$ & $3.36 \pm 0.5$ & $3.30 \pm 0.6$ & 0.9 \\
\hline Após fenilefrina $3 \%$ & $5.01 \pm 1.10$ & $4,00+0.60$ & 0.005 \\
\hline \multicolumn{4}{|l|}{ Área pupilar média $\left(\mathrm{mm}^{2}\right)$} \\
\hline Inicial & $14.88 \pm 4.39$ & $11.25 \pm 3.39$ & 0.009 \\
\hline Após pilocarpina $0.1 \%$ & $8.91 \pm 2.80$ & $8.77 \pm 3.15$ & 0,900 \\
\hline Após fenilefrina $3 \%$ & $21.31 \pm 8.60$ & $12.73 \pm 3.90$ & 0.002 \\
\hline
\end{tabular}


Prata JA, Prata Jünior JA, Castro CN, Macêdo VO, Prata A. A pupila na fase crônica da doença de Chagas e reaçāo à pilocarpina e à fenillefrina. Revista da Sociedade Brasileira de Medicina Tropical 29:567-570, novdez, 1996.

Considerando-se a área pupilar, a comparação entre os dois grupos foi estatisticamente significante para a medida inicial $(p=0,009)$ tendo o grupo chagásico apresentado pupilas com maior área $\left(14,88 \mathrm{~mm}^{2}\right)$ do que nos controles $11,25 \mathrm{~mm}^{2}$ (Tabela 2). Após a instilação de pilocarpina, houve no grupo chagásico maior redução da área pupilar $(36,8 \%)$ do que no grupo controle $(22,1 \%)(\mathrm{p}=0,009)$. Após a instilação de fenilefrina (fase 3) o grupo chagásico apresentou aumento percentual da área pupilar $(150,6 \%)$ comparado aos controles $(56,8 \%)$. Estes resultados foram significantes $(\mathrm{p}=0,001)$.

Nos chagásicos 10 das 20 pupilas (50\%) apresentaram redução de diâmetro maior que um milímetro ao contrário do grupo controle onde apenas uma pupila (5\%) mostrou tal redução. Tais diferenças foram estatisticamente significantes $(p=0,0033)$. Aumento do diâmetro pupilar maior que um milímetro após o uso de fenilefrina foi notado em 13 das 20 pupilas $(65 \%)$ no grupo chagásico e em $3(15 \%)$ no grupo controle, diferença estatisticamente significante $(p=0,003)$.

Os reflexos pupilares estavam presentes e normais.

Em cinco pacientes do grupo chagásico as pupilas mostraram assimetria entre os dois olhos, estas assimetrias não eram intensas, mas facilmente identificáveis. Por exemplo, diâmetro vertical e horizontal diferente em um lado apenas e pupilas de forma oval unilaterais. No grupo controle não foi observada esta ocorrência. Estas diferenças foram estatisticamente significantes $(p=0,03)$. Dos quatro pacientes com anisocoria este tipo de assimetria foi constatado em dois casos.

Quanto às formas clínicas dos pacientes chagásicos (Tabela 1), quatro pertenciam a forma indeterminada (40\%), dois à cardíaca (20\%) e quatro à digestiva ( $40 \%)$. Os casos que apresentaram anisocoria, dois pertenciam a forma indeterminada, um a cardíaca e um a digestiva.

\section{DISCUSSÃO}

O método empregado para a análise da pupila neste estudo mostrou-se satisfatório para execução prática em área endêmica e pelos resultados que proporcionou. Esse método é similar a outros previamente publicados ${ }^{2+5}$. Entretanto, com recursos fotográficos relativamente singelos, que dispensaram uso de equipamentos sofisticados, foi possivel, no campo, fotografar pupilas antes e após a instilação de colírios de pilocarpina e fenilefrina. Posteriormente, usando métodos também simples de fotografia e projeção foi possível efetuar a mensuração das pupilas com recisāo satisfatória.

Neste estudo observamos que o diâmetro médio das pupilas dos pacientes chagásicos, foi significantemente maior do que nos não chagásicos, ou seja, a pupila dos chagásicos examinados foi maior. Tal observação carece de precedência na literatura. Também observamos nos chagásicos uma redução percentual em diâmetro e área da pupila estatisticamente maior com o uso de pilocarpina diluída. Esta maior sensibilidade sugere desnervação parcial parassimpática da íris o que é concordante com o referido por Idiaquez $z^{3}$. Por outro lado, quando foi insitilado fenilefrina $3 \%$ observou-se um aumento percentual em diâmetro e área da pupila estatisticamente superior a dos controles, 0 que indica uma sensibilidade também maior dos chagásicos à fenilefrina. Tais achados sugerem haver nos doentes chagásicos alterações do sistema nervoso autônomo ocular. Pela metodologia empregada não foi possivvel afirmar com precisão se as alterações observadas decorreram de distúrbio somente do sistema parassimpático ou dos sistemas parassimpático e simpático.

A diferença em freqüência de anisocoria neste estudo não foi estatisticamente significante, apesar de termos detectado anisocoria em 40\% dos chagásicos e $10 \%$ dos controles. O critério adotado para caracterizar anisocoria neste estudo baseou-se nas diferenças em diâmetro e área da pupila conforme o previamente apresentado na literatura ${ }^{2+3}$. Por outro lado, observamos diferença estatisticamente significante quanto à assimetria do contorno pupilar entre os grupos. Se acrescentarmos essas alteraçōes de assimetria de contornos pupilares no critério de anisocoria, teríamos $60 \%$ de anisocoria nos chagásicos e $10 \%$ nos controles, diferença esta estatisticamente significante pelo teste exato de Fisher.

Pela análise dos nossos resultados podemos concluir que:

1. O método desenvolvido para o estudo da pupila foi satisfatório; 
Prata JA, Prata Júnior JA, Castro CN, Macêdo VO, Prata A. A pupila na fase crônica da doença de Chagas e reação à pilocarpina e à fenillefrina. Revista da Sociedade Brasileira de Medicina Tropical 29:567-570, novdez, 1996.

2. As pupilas dos chagásicos mostraram-se estatisticamente maiores em diâmetro e área do que os controles;

3. Nos chagásicos observou-se uma contração pupilar estatisticamente maior do que os controles frente ao colírio de pilocarpina $0,1 \%$ e uma maior dilatação pupilar com o uso de colírio de fenilefrina $3 \%$ de forma estatisticamente significante.

\section{SUMMARY}

To develop a method to analyse pupillary disturbances in patients with chronic chagas disease in an endemic area, ten chagasic and ten normal subjects were matched according to sex, age and race. Pupillary diameter and area were determined using projection and topography techniques and compared between groups. Both pupils were visualised simultaneously. In each case three photographs were taken under standardised illumination. The first photo was obtained without medication, the second, 30 minutes after instillation of $.0,1 \%$ pilocarpine and the last 30 minutes after instillation of 3\% phenylepbrine (60 minutes after pilocarpine). Pupils of chagasic patients had a statistically significant greater initial diameter and area, irregularity of the pupil border, greater percentual reduction in diameter and area after pilocarpine $0.1 \%$ and greater percentual increase in diameter and area after $3 \%$ phenylephrine eyedrops. The method developed for this study was considered satisfactory. The results suggest ocular autonomic nervous system disturbances in chagasic patients.

Key-words: Anisocoria. Pupil. Chagas' disease.

\section{AGRADECIMENTOS}

Os autores agradecem ao Sr. Domingos das Virgens, agente de Saúde em Mambaí, pela localização e transporte dos pacientes.

\section{REFERÊNCIAS BIBLIOGRÁFICAS}

1. Atiás A, Morales NM, Nuñoz P, Barría C. El compromisso ocular en la enfermedade de Chagas congênita. Revista Chilena de Pediatria 56:137-141, 1985.

2. Ettinger ER, Wyatt HJ, London R. Anisocoria Investigative Ophthalmology Visual Science 32:501-509, 1991.

3. Idiaquez J. Parasympathetic denervation of the iris in Chagas disease. Clinical Autonomic Research 2:277-279, 1992.

4. Lam BL, Thompson HS, Corbett JJ.The prevalence of simple anisocoria. American Journal of Ophthalmology 104:69, 1987.

5. Loewenfeld IE. Simple central anisocoria. Transactions of the American Academy of
Ophthalmology and Otolaryngology 83:832-839, 1977.

6. Prata A. Classificação da infecção chagásica no homem. Revista da Sociedade Brasileira de Medicina Tropical 23:109-113, 1990.

7. Prata JA, Prata Jr JA, Castro CN, Macedo V, Prata A. Anisocoria na fase crônica da doença de Chagas. Nota prévia. Revista da Sociedade Brasileira de Medicina Tropical 28:131-133, 1995.

8. I Reunião de Pesquisa Aplicada em doença de Chagas. Validade do conceito da forma indeterminada de doença de Chagas. Revista da Sociedade Brasileira de Medicina Tropical 18:46, 1985. 